\title{
The Role of Hydrogen Peroxide in Environmental Adaptation of Oral Microbial Communities
}

\author{
Lin $\mathrm{Zhu}^{1}$ and Jens Kreth ${ }^{2}$ \\ ${ }^{1}$ Department of Periodontics, College of Dentistry, University of Oklahoma Health Sciences Center, Oklahoma City, OK 73104, USA \\ ${ }^{2}$ Department of Microbiology and Immunology, College of Medicine, University of Oklahoma Health Sciences Center, \\ BMSB 907, 940 Stanton L Young Boulevard, Oklahoma City, OK 73104, USA \\ Correspondence should be addressed to Jens Kreth, jkreth@ouhsc.edu
}

Received 10 April 2012; Accepted 11 May 2012

Academic Editor: Ivan Spasojevic

Copyright () 2012 L. Zhu and J. Kreth. This is an open access article distributed under the Creative Commons Attribution License, which permits unrestricted use, distribution, and reproduction in any medium, provided the original work is properly cited.

Oral streptococci are able to produce growth-inhibiting amounts of hydrogen peroxide $\left(\mathrm{H}_{2} \mathrm{O}_{2}\right)$ as byproduct of aerobic metabolism. Several recent studies showed that the produced $\mathrm{H}_{2} \mathrm{O}_{2}$ is not a simple byproduct of metabolism but functions in several aspects of oral bacterial biofilm ecology. First, the release of DNA from cells is closely associated to the production of $\mathrm{H}_{2} \mathrm{O}_{2}$ in Streptococcus sanguinis and Streptococcus gordonii. Extracellular DNA is crucial for biofilm development and stabilization and can also serve as source for horizontal gene transfer between oral streptococci. Second, due to the growth inhibiting nature of $\mathrm{H}_{2} \mathrm{O}_{2}, \mathrm{H}_{2} \mathrm{O}_{2}$ compatible species associate with the producers. $\mathrm{H}_{2} \mathrm{O}_{2}$ production therefore might help in structuring the initial biofilm development. On the other hand, the oral environment harbors salivary peroxidases that are potent in $\mathrm{H}_{2} \mathrm{O}_{2}$ scavenging. Therefore, the effects of biofilm intrinsic $\mathrm{H}_{2} \mathrm{O}_{2}$ production might be locally confined. However, taking into account that $80 \%$ of initial oral biofilm constituents are streptococci, the influence of $\mathrm{H}_{2} \mathrm{O}_{2}$ on biofilm development and environmental adaptation might be under appreciated in current research.

\section{The Oral Biofilm: A Highly Adapted Microbial Consortium}

Oral bacteria residing in the supragingival biofilm have a remarkable degree of structural organization $[1,2]$. This organization is the result of a successive buildup and continuous integration of new species into the developing biofilm. Starting with a cleaned or recently emerged tooth, initial oral streptococcal colonizers adhere via specific surface proteins to salivary proteins covering the tooth surface [1]. Oral streptococci by themselves provide surface proteins for the attachment and integration of other oral bacteria [3]. Initial binding of oral streptococci therefore sets the stage for the development of a mature biofilm community. Beside the physical contact, biofilm development involves several layers of interactions among the biofilm community members. This includes efficient nutrient usage by metabolic cooperativity, communication by small signal molecules, and genetic exchange $[4,5]$.

The crucial steps in initial attachment and biofilm development have been well documented in the past years.
Using specific removable appliances harboring dental enamel chips, Diaz et al. were able to trace the spatiotemporal pattern of oral biofilm formation in the human host [6]. Oral streptococci were the predominant species in the initial colonization stage after 4 and 8 hours. Up to $80 \%$ of the detected initial colonizers belonged to the genus Streptococcus with some species discussed as constant members presenting a core group of initial biofilm formation $[6,7]$. The biofilm developmental process starts with small microcolonies consisting mainly of streptococci and few non-streptococci [6]. This developmental process has implications on other species efforts to join the biofilm community or attach in close proximity. Oral streptococci are known for their production and secretion of antimicrobial substances, one of them is hydrogen peroxide $\left(\mathrm{H}_{2} \mathrm{O}_{2}\right)[8,9]$. The production of antimicrobial substances like $\mathrm{H}_{2} \mathrm{O}_{2}$ could therefore be regarded as an important protection mechanism of the initial colonizers of the resident biofilm community against invading and competing species. More importantly, it might also be a mechanism to shape the colonization process toward a specific 
species composition. Only species coevolved with oral streptococci and therefore adapted to withstand $\mathrm{H}_{2} \mathrm{O}_{2}$ can integrate or colonize in close proximity to the initial colonizers and extend the developing biofilm community.

After initial attachment of streptococci, the biofilm builds up and several other species join the biofilm community $[1,6]$. This also leads to an increase in biofilm thickness and subsequent anaerobic conditions [10-12], which in turn can attract anaerobic bacteria. $\mathrm{H}_{2} \mathrm{O}_{2}$ production inside the oral biofilm most likely declines under these conditions due to insufficient oxygen availability. The role of $\mathrm{H}_{2} \mathrm{O}_{2}$ becomes less important and other factors might influence biofilm maturation. From the perspective of the oral streptococci, $\mathrm{H}_{2} \mathrm{O}_{2}$ fulfills its purpose exactly when it is needed, during initial biofilm formation, when oxygen for $\mathrm{H}_{2} \mathrm{O}_{2}$ production is readily available [13]. The ecological niche of oral streptococci is freely accessible for competing species during initial biofilm formation, and this competition is counteracted either by the direct bactericidal effect of $\mathrm{H}_{2} \mathrm{O}_{2}$ or the preferred integration of compatible species into the growing community. Once the streptococci are established and have built up an association of compatible neighboring biofilm inhabitants, they already occupy their favorite ecological niche and the antimicrobial activity of $\mathrm{H}_{2} \mathrm{O}_{2}$ is no longer required.

The multispecies oral biofilm community provides a protective function to prevent invasion of foreign (pathogenic) bacteria [14]. Unfortunately, some of the bacterial species commonly found in the human oral biofilm consortium have the ability to cause diseases like tooth decay (caries). Under healthy conditions, these species would not cause any harm. Disease development is the result of a disturbed biofilm homeostasis leading to an overgrowth of conditional pathogenic bacteria and a general reduction of the species composition normally found in healthy supragingival plaque $[15,16]$. Interestingly, clinical evidence emerges that some of the $\mathrm{H}_{2} \mathrm{O}_{2}$ producing oral streptococci seem to be reduced in their abundance in subjects having oral diseases like caries or periodontal disease [17-19].

The available in vivo and in vitro studies point to $\mathrm{H}_{2} \mathrm{O}_{2}$ as an important metabolic product generated in the early cycles of oral biofilm formation. In the following sections, specific examples important in biofilm development and in the adaptation to the oral biofilm environment are discussed.

\section{Sources of $\mathbf{H}_{2} \mathbf{O}_{2}$}

$\mathrm{H}_{2} \mathrm{O}_{2}$ in the oral cavity originates from bacteria and from the host [20]. At the present time, it is not clear how both sources influence each other and if at all the production of $\mathrm{H}_{2} \mathrm{O}_{2}$ by the host directly impacts the biofilm and vice versa. $\mathrm{H}_{2} \mathrm{O}_{2}$ has not been detected directly in saliva [21, 22]. The transient concentration has been calculated to be around $10 \mu \mathrm{M}$ based on known concentrations of thiocyanate and hypothiocyanite in saliva [22]. One potential reason is the presence of a salivary scavenging system for $\mathrm{H}_{2} \mathrm{O}_{2}$ to protect the host from $\mathrm{H}_{2} \mathrm{O}_{2}$ toxicity $[23,24]$. Two host-derived peroxidases are present in the human oral cavity, salivary peroxidase, and myeloperoxidase [23]. Both are able to use $\mathrm{H}_{2} \mathrm{O}_{2}$ as an oxidant and thiocyanate as a substrate to produce hypothiocyanite [23]. Interestingly, hypothiocyanite is not only a detoxification product, but also a general antimicrobial substance, and the combination of $\mathrm{H}_{2} \mathrm{O}_{2}$, hypothiocyanite, and salivary peroxidase seems to be most potent in inhibiting bacterial metabolism [25, 26]. Salivary peroxidase, a noninducible component of saliva originates in the parotid and submandibular glands [27]. Myeloperoxidase is an offensive component of polymorphonuclear leukocytes [28], which are present in saliva with elevated levels during inflammatory diseases like periodontal disease [29].

2.1. Sources of $\mathrm{H}_{2} \mathrm{O}_{2}$ in the Oral Biofilm. Oral streptococci have long been known to produce $\mathrm{H}_{2} \mathrm{O}_{2}$, mainly due to their ability to inhibit various other species in in vitro tests. Early reports already indicate that $\mathrm{H}_{2} \mathrm{O}_{2}$ production might be widely distributed among oral streptococci. Thompson and Shibuya tested 55 alpha-hemolytic oral streptococci and found that 48 were able to inhibit the growth of Corynebacterium diphtheria [30]. Tests with identified streptococcal species showed that Streptococcus oralis, Streptococcus mitis, Streptococcus sanguinis, and Streptococcus sobrinus all were able to produce significant amounts of $\mathrm{H}_{2} \mathrm{O}_{2}$ during growth in vitro, which can be detected in the supernatants of the growth medium [31]. These oral streptococci are commonly isolated and present in a relatively high abundance in the human oral biofilm [32]. Variations in $\mathrm{H}_{2} \mathrm{O}_{2}$ production among streptococci were shown to be growth medium and carbohydrate dependent [31], indicating environmental influences on regulatory mechanisms of $\mathrm{H}_{2} \mathrm{O}_{2}$ production.

The enzyme responsible for the production of $\mathrm{H}_{2} \mathrm{O}_{2}$ in $S$. sanguinis and $S$. gordonii was identified as pyruvate oxidase, encoded by gene $\operatorname{sp} x B$ (also referred to as pox) [33-35]. The pyruvate oxidase is an oxidoreductase that catalyzes the conversion of pyruvate, inorganic phosphate $\left(\mathrm{P}_{\mathrm{i}}\right)$, and molecular oxygen $\left(\mathrm{O}_{2}\right)$ to $\mathrm{H}_{2} \mathrm{O}_{2}$, carbon dioxide $\left(\mathrm{CO}_{2}\right)$, and the highenergy phosphoryl group donor acetyl phosphate in an aerobic environment. Genetic inactivation of the respective open reading frames encoding for putative pyruvate oxidase orthologs in S. sanguinis and S. gordonii confirmed the pyruvate oxidase as the enzyme responsible for significant $\mathrm{H}_{2} \mathrm{O}_{2}$ production [35]. The production of growth inhibiting amounts of $\mathrm{H}_{2} \mathrm{O}_{2}$ is not exclusive to the pyruvate oxidase in oral streptococci. Detailed genetic inactivation studies in Streptococcus oligofermentans showed that at least two other enzymes in addition to the pyruvate oxidase are able of producing growth-inhibiting amounts of $\mathrm{H}_{2} \mathrm{O}_{2}[36,37]$. The lactate oxidase, gene $l c t O$ (also referred to as lox), catalyzes the formation of pyruvate and $\mathrm{H}_{2} \mathrm{O}_{2}$ from L-lactate and oxygen and an L-amino acid oxidase generates $\mathrm{H}_{2} \mathrm{O}_{2}$ from amino acids and peptones. Dual species biofilm antagonism assays with $S$. oligofermentans and $S$. mutans demonstrated that the $\mathrm{H}_{2} \mathrm{O}_{2}$ produced by LctO activity is still able to antagonize $S$. mutans in an spxB background. The role of the $\mathrm{L}$-amino acid oxidase in interspecies competition is not clear since its $\mathrm{H}_{2} \mathrm{O}_{2}$ producing activity is low, and only visible in a lctO/spxB double knockout mutant $[36,38]$. Nonetheless, the L-amino acid oxidase seems to be important as suggested 
TABle 1: Distribution and nucleotide identity of $\operatorname{spxB}$ and lctO among sequenced oral streptococcal isolates.

\begin{tabular}{|c|c|c|c|}
\hline Species & Strain & $\begin{array}{c}s p x B \text { identity } \\
(\%)\end{array}$ & $\begin{array}{c}\text { lctO identity } \\
(\%)\end{array}$ \\
\hline \multirow{8}{*}{ S. mitis } & B6 & 100 & 100 \\
\hline & NCTC 12261 & 97 & 95 \\
\hline & SK564 & 97 & 95 \\
\hline & SK321 & 97 & 94 \\
\hline & SK597 & 96 & 94 \\
\hline & F0392 & 96 & 93 \\
\hline & SK95 & 96 & - \\
\hline & ATCC 6249 & 96 & 90 \\
\hline \multirow{3}{*}{ S. sanguinis } & SK36 & 94 & - \\
\hline & SK49 & 95 & - \\
\hline & AATCC 49296 & 96 & 91 \\
\hline S. gordonii & $\mathrm{CH} 1$ & 96 & - \\
\hline \multirow{2}{*}{ S. oralis } & Uo5 & 96 & 91 \\
\hline & ATCC 35037 & 96 & 91 \\
\hline S. parasanguinis & SK236 & 95 & 一 \\
\hline \multirow{2}{*}{ S. vestibularis } & FO396 & 95 & - \\
\hline & ATCC 49124 & 95 & - \\
\hline S. peroris & ATCC 700780 & 95 & 90 \\
\hline S. cristatus & ATCC 51100 & - & 87 \\
\hline S. oligofermentans & AS 1.3089 & 95 & 88 \\
\hline
\end{tabular}

by a recent study, Boggs et al. showed that the L-amino acid oxidase gene aao from S. oligofermentans was probably acquired via horizontal gene transfer from a source closely related to S. sanguinis and S. gordonii, while evolutionary $S$. oligofermentans seems to be more closely related to $S$. oralis, S. mitis, and S. pneumoniae [39]. The authors speculate that the aao gene is important for S. oligofermentans to occupy a specific ecological niche in the oral biofilm [39]. The regulation of aao gene expression is not known, and the gene might be induced under specific conditions in vivo.

Using the available genome sequence data from the Human Oral Microbiome Database (http://www.homd .org/), the distribution of $s p \times B$ and $l c t O$ among oral streptococci was determined using $s p x B$ and $l c t O$ from $S$. mitis $\mathrm{B} 6$ as a template. As shown in Table 1, several important oral streptococci encode open reading frames with a high homology to $s p x B$ and $l c t O$. All species listed in Table 1 are commonly isolated from subjects suggesting a wide distribution of $s p x B$ and $l c t O$ in oral streptococci. Interestingly, $s p x B$ seemed to be more conserved among species when compared to lctO. The relatively wide distribution of $\operatorname{sp} x B$ and $l c t O$ and the high degree of conservation suggest that both genes play an important role in the $\mathrm{H}_{2} \mathrm{O}_{2}$ production capabilities of the oral biofilm and might be considered as oral streptococcal community genes. Interestingly, inactivation of $s p x B$ in $S$. sanguinis diminishes competitive $\mathrm{H}_{2} \mathrm{O}_{2}$ production, suggesting that LctO plays no role in interspecies competition under the tested conditions in S. sanguinis [35].
2.2. Sources of $\mathrm{H}_{2} \mathrm{O}_{2}$ from the Host. $\mathrm{H}_{2} \mathrm{O}_{2}$ originates from several sources in the human body. Mitochondria are wellknown producers of reactive oxygen species (ROS) as a byproduct of respiration [40]. Effective intracellular scavenging systems are in place to avoid ROS inflicted damage [41] and the $\mathrm{H}_{2} \mathrm{O}_{2}$ might not leave the oral mucosa in sufficient amounts to play a role in oral microbial biofilm ecology. A regulated production of ROS is observed as part of the oxidative burst from phagocytic cells [42]. The ROS production is directed towards the outsides of the phagocytic cell to defend the host from microbial pathogens and might therefore freely diffuse to nearby locations. Polymorphonuclear leukocytes seem to be the predominant phagocytic cells in saliva originating from the gingival crevice fluid and are constantly replenished [29]. However, one study with healthy individuals observed a high intraindividual dayto-day variability of salivary polymorphonuclear leukocyte content [43], making it difficult to judge how much $\mathrm{H}_{2} \mathrm{O}_{2}$ is being released as a consequence of phagocytic cell activity.

A more constant source of $\mathrm{H}_{2} \mathrm{O}_{2}$ supplied into saliva could originate from salivary gland cells expressing the dual oxidase 2 gene (Duox2) as shown by Geiszt et al. [44]. The same study also suggests that that ROS production occurs in the last step of saliva formation for direct delivery of ROS into the oral cavity $[42,44]$ and could therefore be the major source for salivary $\mathrm{H}_{2} \mathrm{O}_{2}$ originating from the host.

\section{Hydrogen Peroxide in Oral Bacterial Ecology}

3.1. Where Does It Matter: The Importance of Bacterial Proximity. The fact that $\mathrm{H}_{2} \mathrm{O}_{2}$ was never detected in saliva so far and the existence of a major scavenging system comprised of salivary peroxidases raise an important question: how likely does $\mathrm{H}_{2} \mathrm{O}_{2}$ affect oral bacterial ecology or aid in biofilm community adaptation? This question might be addressed by the fact that a bacterial biofilm comprises its own microcosm with intrinsic biofilm $\mathrm{H}_{2} \mathrm{O}_{2}$ production and most likely has a localized effect due to diffusion restrictions. By measuring the $\mathrm{H}_{2} \mathrm{O}_{2}$ concentration produced by single species, $S$. gordonii biofilms, Liu et al. were able to show that a steady state level of $1.4 \mathrm{mM} \mathrm{H}_{2} \mathrm{O}_{2}$ was produced at a distance of $100 \mu \mathrm{m}$ above the biofilm surface [45]. Only $0.4 \mathrm{mM} \mathrm{H}_{2} \mathrm{O}_{2}$ is produced when measured $200 \mu \mathrm{m}$ above the biofilm. This localized production of $1.4 \mathrm{mM}$ is a concentration able to inhibit $\mathrm{H}_{2} \mathrm{O}_{2}$ susceptible bacteria, which have to be in close proximity. Remarkably, the same study also measured higher concentrations of $\mathrm{H}_{2} \mathrm{O}_{2}$ close to the surface of the biofilm as compared to planktonic grown cells [45]. This is in contrast to an earlier study by Nguyen et al. showing that $S$. sanguinis and $S$. gordonii had lower $\mathrm{H}_{2} \mathrm{O}_{2}$ production rates in biofilms when compared to planktonic cells [46]. This discrepancy might be partially explainable by the advanced method used in the study by Liu et al., allowing realtime detection with an $\mathrm{H}_{2} \mathrm{O}_{2}$ specific probe measuring directly above the biofilm surface [45]. Also, the study by Nguyen et al. used a higher concentration of glucose in the growth media, which might have repressed the $\mathrm{H}_{2} \mathrm{O}_{2}$ production rate [46] (see below: regulatory studies on $\mathrm{H}_{2} \mathrm{O}_{2}$ production). The difference in $\mathrm{H}_{2} \mathrm{O}_{2}$ concentration as a function of biofilm surface distance 


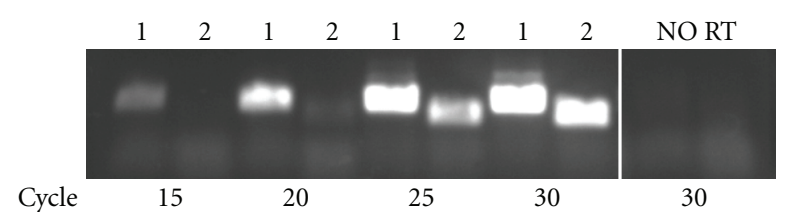

Figure 1: Expression of $s p x B$ in freshly isolated human plaque. To detect the expression of $s p x B$ among streptococcal species in the oral biofilm, plaque samples were collected from a healthy subject without active caries. Bacterial RNA was isolated and cDNA synthesized after standard protocols [59]. The $s p x B$ gene was PCR amplified from the synthesized cDNA with primers described by us earlier specific for $s p x B$ and $16 S$ rRNA [59]. Samples were removed during the PCR run after 15, 20, 25, and 30 PCR cycles and loaded on an agarose gel for visualization. $1=16 \mathrm{~S}$ rRNA; $2=\operatorname{spxB}$; no $\mathrm{RT}=$ control for chromosomal DNA contamination.

supports the suggestion that $\mathrm{H}_{2} \mathrm{O}_{2}$ producing species most likely have an effect on close neighboring species. When the cells dislodge and enter a planktonic state, $\mathrm{H}_{2} \mathrm{O}_{2}$ production becomes irrelevant. Taking into account that the oral biofilm is a diffusion barrier for larger proteins and molecules [47], the intrinsic $\mathrm{H}_{2} \mathrm{O}_{2}$ production of biofilm would also be more protected against the action of salivary lactoperoxidases, which might not penetrate preformed biofilms [48].

Detection of actual $s p \times B$ expression in the human oral biofilm would support the importance of $s p x B$-dependent $\mathrm{H}_{2} \mathrm{O}_{2}$ production. If $\operatorname{sp} x \mathrm{~B}$ plays a vital role in oral biofilm ecology, one would expect that cells residing in the human oral biofilm express the $s p x B$ gene. Using freshly isolated plaque samples from a subject with no active caries, $s p x B$ specific cDNA was synthesized from RNA isolated from human oral biofilm bacteria and $\operatorname{sp} x B$ expression confirmed (Figure 1; unpublished results). This observation not only shows for the first time the expression of an oral biofilm relevant gene in vivo but also strongly supports $s p x B$ relevance in the human dental plaque and suggests that $\operatorname{sp} x B$ plays a role in biofilm specific processes.

3.2. Adaptation to a Competitive Environment-Genetic Exchange. Adaptation to the constantly changing oral environment requires some kind of genetic flexibility. This can be achieved by specific gene expression regulation and the adjustment of the transcriptome to sudden perturbations in the environment or by the acquisition of new genetic traits to cope with long-term environmental changes. Oral streptococci are known for their natural ability to take up extracellular DNA, a physiological state called competence [49]. Bacterial competence has long been recognized as the ability to take up DNA, but recent studies show that competence is part of a larger stress response, which enables competent bacteria to cope with a stressful environment [50]. Competent oral streptococci are able to take up homologous and heterologous DNA [51-53]. This increases the available DNA pool and allows for acquisition of new genetic traits from other species. Expression of newly acquired genetic traits depends on the homologous recombination of the incorporated DNA into the host chromosome $[54,55]$.
The mechanisms and genetic regulation of natural competence leading to the uptake and integration of DNA via homologous recombination are documented in numerous studies, and the basic blueprint of competence seems to be similar among oral streptococci $[49,56]$. What is less known is how the biofilm community generates the extracellular DNA for DNA uptake by competent bacteria. A general mechanism of bacteria to produce extracellular DNA is an autolytic event leading to bacterial disintegration. Recent studies show that autolysis is a regulated process.

The release of DNA into the environment by $S$. gordonii and $S$. sanguinis is closely associated with the production of $\mathrm{H}_{2} \mathrm{O}_{2}$ [35]. The wild type organisms release high molecular weight DNA during aerobic growth, which was shown to be of chromosomal origin [57]. A deletion of the pyruvate oxidase gene affected this release process dramatically [57]. In addition, a significant reduced concentration of extracellular DNA was detected under oxygen limited growth conditions [58], correlating with a reduced expression of $s p \times B$ and a lower amount of SpxB $[59,60]$. Further studies showed that $\mathrm{H}_{2} \mathrm{O}_{2}$ is the only requirement to induce the DNA release process. Addition of $\mathrm{H}_{2} \mathrm{O}_{2}$ to anaerobically grown cells does induces DNA release. Although mechanistic studies are still in progress and the release process is not fully understood, our group has demonstrated a correlation between $\mathrm{H}_{2} \mathrm{O}_{2}$ induced DNA damage and extracellular DNA generation. Treatment with DNA damaging agents like UV light and mitomycin $\mathrm{C}$ also triggered the release of DNA under anaerobic conditions [58].

Initial evidence of an autolytic activity involved in the DNA release process comes from Robert A. Burne's group, showing that the major autolysin AtlS is involved in DNA release [61]. A deletion of AtlS in S. gordonii prevented autolysis under aerobic conditions, and as a consequence, a decreased production of extracellular DNA was observed [61]. Their observation, however, is in contrast to an observation by our group, showing that under anaerobic conditions, extracellular DNA release can be induced by $\mathrm{H}_{2} \mathrm{O}_{2}$ addition without any obvious bacterial cell lysis [58]. A possible explanation for these observations is that streptococci may have several mechanisms to trigger lysis responding to different internal and/or external stimuli. Autolysis may also not necessarily mean complete lysis of the bacterial cell or might only affect a small portion of the population. A recent report showed that $S$. gordonii expresses a murein hydrolase, $L y t F$, involved in competence dependent bacterial lysis [62]. In fact, $l y t F$ is only expressed during competence because its expression is under the control of the competence stimulating peptide CSP, a small secreted peptide which accumulates in the environment after reaching a critical threshold concentration initiating the competence signaling cascade (see [50] for a detailed overview of competence in bacteria). DNA transfers experiments relying on LytF dependent cell lysis, and subsequent DNA uptake by $S$. gordonii showed that most cells are protected from the muralytic activity of LytF [62]. This is in agreement with our observation of a lysis resistant population [57, 58]. A close association, however, of $\mathrm{H}_{2} \mathrm{O}_{2}$ induced release of DNA and competence development is evident since cells 
grown under $\mathrm{H}_{2} \mathrm{O}_{2}$ producing conditions are also induced for competence development [58]. Interestingly, competence development in $S$. pneumoniae can be initiated by mitomycin $\mathrm{C}$ induced DNA damage, which also leads to the release of DNA [63]. This is reminiscent of our observation that DNA damaging agents induce DNA release [58], which is associated with the ecological advantage of $\mathrm{H}_{2} \mathrm{O}_{2}$ induced DNA release and the adaptation of oral streptococci to stress. S. gordonii and probably other $\mathrm{H}_{2} \mathrm{O}_{2}$-producing oral streptococci release DNA into the environment as a consequence of DNA damage. This pool of released DNA likely contains mutations in various genes because of the DNA damage. If such mutated DNA is taken up and integrated into the chromosome, the transformation event would lead to a bacterium able to grow and outcompete bacteria without the respective mutation under selective conditions. Even nonmutated extracellular DNA or genes would be useful as a template for the repair of stress-induced DNA damage [58]. The extracellular DNA is precisely produced at a time when it is biologically meaningful, under aerobic conditions during initial biofilm formation with its fierce interspecies competition and environmental stress, hence, when the cells are most competent for DNA transformation. Finally, $\mathrm{H}_{2} \mathrm{O}_{2}$ can also cause the release of DNA from streptococci not producing $\mathrm{H}_{2} \mathrm{O}_{2}$, but the mechanism for this is not known (unpublished results).

3.3. The Other Role of Extracellular DNA. Besides providing genetic information for transformation of competent oral streptococci, the DNA released as a consequence of $\mathrm{H}_{2} \mathrm{O}_{2}$-production might aid in initial biofilm development [64]. Although not directly shown for $\mathrm{H}_{2} \mathrm{O}_{2}$ producing oral streptococci, studies with $S$. mutans demonstrate the importance of extracellular DNA in initial adhesion. Das et al. showed that adhesion kinetics in the presence and absence of naturally occurring extracellular DNA were different. $S$. mutans cells adhered better and in greater numbers to the provided test surface when extracellular DNA was present $[65,66]$.

Initial biofilm formation involves the adhesion of pioneer colonizers to the tooth surface [3]. Another important event in early biofilm formation is bacteria-bacteria aggregation: (1) aggregation of bacteria before the actual attachment event in saliva increases the cluster size of bacteria able to adhere; (2) bacterial aggregation will also aid in the recruitment of other bacteria into the developing biofilm. Although aggregation of bacteria is well described with the identification of several surface proteins involved in the process [3], the role of extracellular DNA in oral bacterial aggregation is not well investigated. Studies with fresh water bacteria show that the released DNA functions in a netlike manner able to trap bacteria [67]. Initial evidence shows that extracellular DNA plays a role in the intraspecies aggregation of S. sanguinis. When grown as a planktonic culture, addition of extracellular DNA degrading DNase inhibits partially the aggregation [57]. Further studies are required to fully understand the role of extracellular DNA in multispecies biofilm formation and bacterial aggregation.

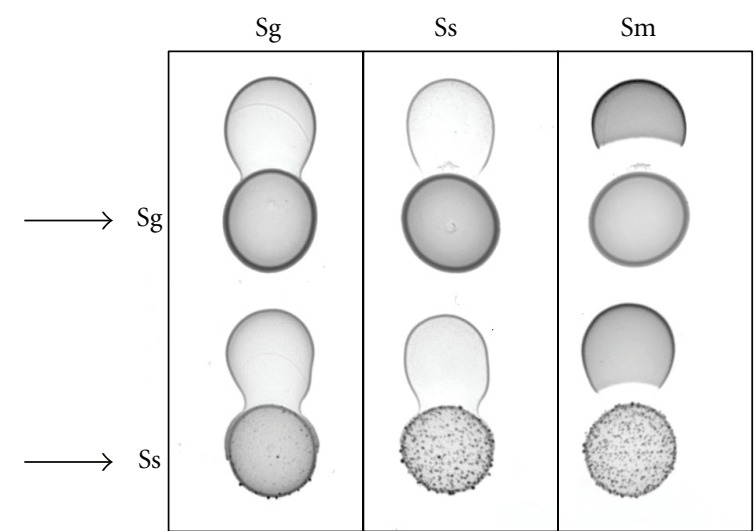

FIgure 2: Oral streptococcal antagonism assay with S. sanguinis, $S$. gordonii, and S. mutans. The lower row in the plate dualspecies antagonism assay were inoculated first (indicated by an arrow) and allowed to grow for $16 \mathrm{~h}$. Subsequently, the to be tested species was inoculated in close proximity. Diffusible $\mathrm{H}_{2} \mathrm{O}_{2}$ produced by $S$. sanguinis ( $\mathrm{Ss}$ ) and $S$. gordonii $(\mathrm{Sg})$ during growth caused inhibition of $S$. mutans (Sm), while no obvious growth inhibition was observed when S. sanguinis or S. gordonii was tested against themselves or against each other.

3.4. Biofilm Community Development. Earlier clinical studies have demonstrated the inverse relationship between $S$. sanguinis and cariogenic $S$. mutans $[17,19]$. A recent study showed that $S$. oligofermentans is also frequently isolated from healthy human subjects [68]. The clinical evidence suggests that the initial colonization by $\mathrm{H}_{2} \mathrm{O}_{2}$-producing bacteria has a beneficial aspect for the human host with regard to caries development, possibly through the influential role of $\mathrm{H}_{2} \mathrm{O}_{2}$ on biofilm community development. Detailed in vitro experiments and relevant biofilm studies confirmed that $S$. sanguinis, $S$. gordonii, and $S$. oligofermentans produce $\mathrm{H}_{2} \mathrm{O}_{2}$ to inhibit S. mutans $[8,35,37]$. Although, the produced $\mathrm{H}_{2} \mathrm{O}_{2}$ has a slight self-inhibitory effect on the producing species in batch cultures, no obvious inhibition occurs when $\mathrm{H}_{2} \mathrm{O}_{2}$ producers are tested against each other in an antagonistic plate diffusion assay (Figure 2). As a consequence, community development favors integration of species that are compatible with the production of $\mathrm{H}_{2} \mathrm{O}_{2}$. Jakubovics et al. showed an interesting relationship between $\mathrm{S}$. gordonii and Actinomyces naeslundii. Although A. naeslundii is severely inhibited in the aforementioned antagonistic plate diffusion assay, coaggregation cultures showed that both species could grow together in close proximity $[69,70]$. S. gordonii is, however, the dominant species in this consortium, leading to a ratio of about 9 to 1 . S. gordonii might benefit from this relationship by the fact that the $\mathrm{H}_{2} \mathrm{O}_{2}$ degrading catalase produced by $A$. naeslundii can reduce oxidative damage to S. gordonii proteins inflicted by its own $\mathrm{H}_{2} \mathrm{O}_{2}$ [70]. The low ratio of $A$. naeslundii to $S$. gordonii would still allow for sufficient inhibition of $\mathrm{H}_{2} \mathrm{O}_{2}$ susceptible species, but a clear ecological niche is necessary to support growth of both species, which could lead to the formation of more stable plaque communities. Another common oral isolate found in close association with S. gordonii is Veillonella ssp. [71]. 
Both species interact at the physiologic and metabolic level as shown by several studies [72-74]. Some strains of Veillonella also produce catalase, indicating that a similar effect as described for $A$. naeslundii might exist in the relationship between S. gordonii and Veillonella ssp. The biological relevance of the interactions between Streptococci, Veillonella, and Actinomyces has recently been demonstrated in vivo by confirming the spatial association of the three species in human plaque samples [2]. Further studies are required to determine the exact role of catalase production in the dual species relationship between $\mathrm{H}_{2} \mathrm{O}_{2}$-producing streptococci and catalase-expressing species.

The production of $\mathrm{H}_{2} \mathrm{O}_{2}$ seems to select for a close association with compatible bacteria during biofilm community development. Therefore, $\mathrm{H}_{2} \mathrm{O}_{2}$ might shape the colonization pattern during initial biofilm formation and provide an ecological advantage for the producer and the accompanying $\mathrm{H}_{2} \mathrm{O}_{2}$ resistant species.

\section{Regulatory Studies on $\mathrm{H}_{2} \mathrm{O}_{2}$ Production}

S. gordonii and S. sanguinis. A detailed analysis of environmental influences on $S$. gordonii's $\mathrm{H}_{2} \mathrm{O}_{2}$ production showed two important behaviors. (1) During growth under limited glucose and sucrose availability, S. gordonii produces only $\mathrm{H}_{2} \mathrm{O}_{2}$, while $\mathrm{H}_{2} \mathrm{O}_{2}$ and L-lactic acid are produced in equal amounts when concentrations of carbohydrates were higher than $0.1 \mathrm{mM}$. Since lower carbohydrate availability means increased competition among the biofilm microflora, a switch to only $\mathrm{H}_{2} \mathrm{O}_{2}$ production might increase the ecological competitiveness. (2) High glucose and sucrose concentrations inhibit the production of $\mathrm{H}_{2} \mathrm{O}_{2}$ [75]. This observation prompted us to further investigate the mechanism of $\mathrm{H}_{2} \mathrm{O}_{2}$ production control by determining $s p x B$ expression and $\mathrm{SpxB}$ abundance in $S$. sanguinis and $S$. gordonii under different environmental conditions. We could confirm the influence of carbohydrate concentration on $s p x B$ expression and abundance showing glucose repression in S. gordonii [59]. The carbohydrate dependent repression of $s p \times B$ expression was also confirmed for galactose, maltose, and lactose, while sucrose and fructose seemed to have no effect in our strain [59]. This indicates that strain variability among $S$. gordonii might exist in the regulation of $s p x B$ expression. A detailed analysis of the promoter region of $s p x B$ from $S$. gordonii showed the existence of two putative binding sites for the catabolite control protein A (CcpA). CcpA is the main regulator of carbon catabolite repression in Grampositive bacteria [76]. Mutational analysis of the promoter sequence confirmed the role of the CcpA binding sites and purified CcpA was able to bind to the respective regions in in vitro electromobility shift assays [59]. Surprisingly, the $s p x B$ expression in S. sanguinis is not influenced by carbohydrate availability, despite a high degree of promoter homology between both species and the presence of respective CcpA binding sites. However, a deletion of CcpA in S. sanguinis increased expression of $s p x B$ several folds [77]. This suggests that $S$. sanguinis constantly represses the expression of $s p x B$ or only lifts the repression due to a yet unknown environmental signal. One reason for this alternative $s p x B$ expression control could be $S$. sanguinis increased susceptibility to $\mathrm{H}_{2} \mathrm{O}_{2}$ when compared to $S$. gordonii (unpublished results). By keeping the production of $\mathrm{H}_{2} \mathrm{O}_{2}$ low, S. sanguinis might prevent self-damage of cellular components like surface adhesins, making it less competitive in the oral environment. The observation that monospecies biofilms of a S. sanguinis CcpA mutant had a higher proportion of dead cells when compared to the wild type further supports this hypothesis [77].

Both species do not produce competitive $\mathrm{H}_{2} \mathrm{O}_{2}$ under anaerobic growth conditions. Accordingly, $s p x B$ expression and $\mathrm{SpxB}$ abundance is greatly reduced under anaerobic growth conditions, but the protein is still detectable $[59,60]$. This finding suggests that both streptococci keep a low level of SpxB present to remain competitive once they encounter aerobic conditions. The mechanisms of oxygen-dependent $s p \times B$ expression control are not known at this time.

The $s p \times B$ expression control involves additional regulators and proteins. Most notable is the identification of an SpxR homolog in S. sanguinis [78]. SpxR was originally identified in $S$. pneumoniae and it was hypothesized that SpxR in $S$. pneumoniae regulates $s p x B$ transcription in response to the energy and metabolic state of the cell [79]. Although not confirmed experimentally, this regulatory function might well be active in S. sanguinis, since no carbohydrate-dependent regulation was detected. Future research might address this question and identify what actual signal is involved in $s p x B$ regulation in S. sanguinis.

S. oligofermentans. S. oligofermentans developed an interesting mechanism to produce antagonistic $\mathrm{H}_{2} \mathrm{O}_{2}$ and maximize its competitiveness. SpxB produces the majority of $\mathrm{H}_{2} \mathrm{O}_{2}$ during active growth [36] leading to the generation of an extra ATP through the $s p x B$ pathway. This ATP provides a metabolic growth advantage in addition to the ecological advantage of $\mathrm{H}_{2} \mathrm{O}_{2}$ production. The lctO-dependent $\mathrm{H}_{2} \mathrm{O}_{2}$ generation on the other hand is more prominent in the early stationary phase, due to an increased availability of lactate [36]. Several other oral streptococci encode genes for both $\mathrm{H}_{2} \mathrm{O}_{2}$ forming enzymes suggesting a similar role in $\mathrm{H}_{2} \mathrm{O}_{2}$ production. This dual SpxB/LctO presence indicates that even under starving conditions, oral streptococci might still produce competitive amounts of $\mathrm{H}_{2} \mathrm{O}_{2}$ to shape biofilm development towards a health compatible composition.

\section{5. $\mathbf{H}_{2} \mathrm{O}_{2}$ in Oral Bacterial-Host Interactions}

Oral streptococcal interactions occur in the mouth and therefore in close proximity to human host cells and the mucosal surface. Interactions with human innate immunity components are inevitable. Marvin Whiteley's group showed that the production of $\mathrm{H}_{2} \mathrm{O}_{2}$ has an unexpected effect on the recognition of pathogenic species by the immune response [80]. Using the recognized periodontal pathogen Aggregatibacter actinomycetemcomitans and S. gordonii as model organisms to study a combined effect on the host innate immune response, they described an interesting relationship between both species. Not only is A. actinomycetemcomitans able to effectively use the lactic acid produced by $S$. gordonii 


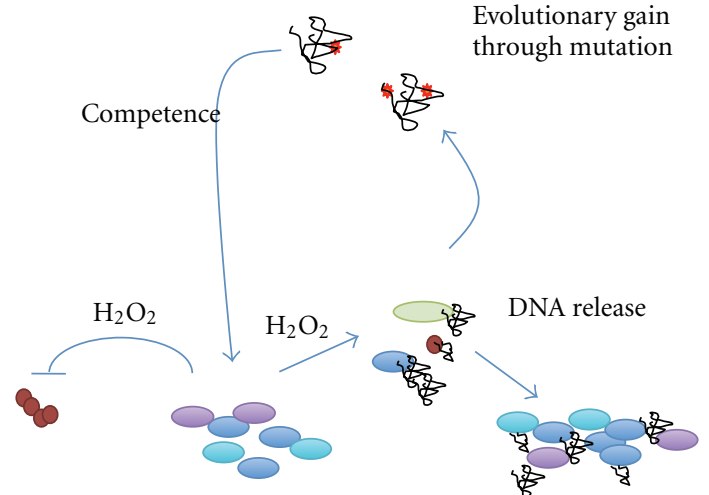

Eliminate competitors and promote $\mathrm{H}_{2} \mathrm{O}_{2}$ compatible microflora

Promote biofilm formation

Figure 3: Overview of the effects of $\mathrm{H}_{2} \mathrm{O}_{2}$ production on oral biofilm development. Initially, the antagonistic effect of streptococcal $\mathrm{H}_{2} \mathrm{O}_{2}$ production was described. As a consequence, competitors are eliminated, and the integration of $\mathrm{H}_{2} \mathrm{O}_{2}$ compatible species into the developing biofilm is promoted. $\mathrm{H}_{2} \mathrm{O}_{2}$ production also causes the release of DNA into the environment. The extracellular DNA promotes biofilm formation and cell-cell aggregation. In addition, $\mathrm{H}_{2} \mathrm{O}_{2}$ causes DNA damage, which in turn could lead to beneficial mutations in competent oral streptococci uptake of extracellular DNA. Extracellular DNA could therefore support adaptational processes to changing environmental conditions and promote evolution of oral biofilm development.

for growth [81] but it also responded to $\mathrm{H}_{2} \mathrm{O}_{2}$ as a signal to induce the expression of an immune evasion gene, apiA. This gene encodes an outer membrane protein able to bind factor $\mathrm{H}$, conferring protection against killing by the alternative complement component of the innate immunity. In addition, the kat $A$ gene encoding cytoplasmic catalase is also induced, conferring resistance to the destructive action of $\mathrm{H}_{2} \mathrm{O}_{2}$ on A. actinomycetemcomitans cellular components [80].

This observation demonstrates that biofilm community development is capable of remarkable evolutionary adaptations and that $\mathrm{H}_{2} \mathrm{O}_{2}$ plays a prominent role in the process of oral biofilm development (Figure 3).

\section{Concluding Remarks}

One of the most important problems in current oral microbial research is to confirm biological relevance of in vitro experimental results. Accepted animal models to simulate oral biofilm ecology are generally rodent models. Although these models increase complexity, the transplanted human oral flora faces a rodent oral microbial consortium and a distinct oral environment. It therefore competes with species and conditions not encountered under normal conditions. It is not known if this complexity affects competition studies. A recent rodent study actually questions the validity of the importance of $\mathrm{H}_{2} \mathrm{O}_{2}$ production in S. gordonii competitiveness. Performing coinoculation studies in rats, Tanzer et al. showed that $S$. mutans is always able to outcompete
S. gordonii under all experimental conditions [82]. Unfortunately, it was not determined whether the S. gordonii strain in their study produced competitive amounts of $\mathrm{H}_{2} \mathrm{O}_{2}$ or if the $s p x B$ gene was expressed in the rat oral biofilm. It is also unclear if the respective $S$. mutans strain was $\mathrm{H}_{2} \mathrm{O}_{2}$ susceptible. It is therefore important that animal studies about ecological questions actually demonstrate that the respective competitive gene set(s) are expressed under animal test conditions. It is also important to verify the expression of the gene(s) of interest in the human oral biofilm. Our initial data for $s p x B$ gene expression in the human oral biofilm are promising and warrant further research regarding the ecological role of $\mathrm{H}_{2} \mathrm{O}_{2}$ production in human oral biofilm.

\section{Acknowledgments}

J. Kreth was supported by NIH/NIDCR Grant R00DE018400. The authors thank Dr. J. Ferretti (Department of Microbiology \& Immunology, University of Oklahoma HSC) for helpful comments.

\section{References}

[1] P. E. Kolenbrander, R. J. Palmer Jr., A. H. Rickard, N. S. Jakubovics, N. I. Chalmers, and P. I. Diaz, "Bacterial interactions and successions during plaque development," Periodontology 2000, vol. 42, no. 1, pp. 47-79, 2006.

[2] A. M. Valm, J. L. Mark Welch, C. W. Rieken et al., "Systemslevel analysis of microbial community organization through combinatorial labeling and spectral imaging," Proceedings of the National Academy of Sciences of the United States of America, vol. 108, no. 10, pp. 4152-4157, 2011.

[3] A. H. Nobbs, R. J. Lamont, and H. F. Jenkinson, "Streptococcus adherence and colonization," Microbiology and Molecular Biology Reviews, vol. 73, no. 3, pp. 407-450, 2009.

[4] P. E. Kolenbrander, P. G. Egland, P. I. Diaz, and R. J. Palmer Jr., "Genome-genome interactions: bacterial communities in initial dental plaque," Trends in Microbiology, vol. 13, no. 1, pp. 11-15, 2005.

[5] P. E. Kolenbrander, R. J. Palmer Jr., S. Periasamy, and N. S. Jakubovics, "Oral multispecies biofilm development and the key role of cell-cell distance," Nature Reviews Microbiology, vol. 8, no. 7, pp. 471-480, 2010.

[6] P. I. Diaz, N. I. Chalmers, A. H. Rickard et al., "Molecular characterization of subject-specific oral microflora during initial colonization of enamel," Applied and Environmental Microbiology, vol. 72, no. 4, pp. 2837-2848, 2006.

[7] B. Rosan and R. J. Lamont, "Dental plaque formation," Microbes and Infection, vol. 2, no. 13, pp. 1599-1607, 2000.

[8] J. Kreth, J. Merritt, W. Shi, and F. Qi, "Competition and coexistence between Streptococcus mutans and Streptococcus sanguinis in the dental biofilm," Journal of Bacteriology, vol. 187, no. 21, pp. 7193-7203, 2005.

[9] C. S. Ryan and I. Kleinberg, "Bacteria in human mouths involved in the production and utilization of hydrogen peroxide," Archives of Oral Biology, vol. 40, no. 8, pp. 753-763, 1995.

[10] D. J. Bradshaw, P. D. Marsh, G. Keith Watson, and C. Allison, "Role of Fusobacterium nucleatum and coaggregation in anaerobe survival in planktonic and biofilm oral microbial communities during aeration," Infection and Immunity, vol. 66, no. 10, pp. 4729-4732, 1998. 
[11] P. S. Stewart and M. J. Franklin, "Physiological heterogeneity in biofilms," Nature Reviews Microbiology, vol. 6, no. 3, pp. 199-210, 2008.

[12] M. Wilson, "The oral cavity and its Indigious microbiota," in Microbial Inhabitants of Humans, pp. 318-372, Cambridge University Press, Cambridge, UK, 2005.

[13] R. E. Marquis, "Oxygen metabolism, oxidative stress and acidbase physiology of dental plaque biofilms," Journal of Industrial Microbiology, vol. 15, no. 3, pp. 198-207, 1995.

[14] P. D. Marsh, "Dental plaque as a biofilm: the significance of $\mathrm{pH}$ in health and caries," Compendium of Continuing Education in Dentistry, vol. 30, pp. 76-90, 2009.

[15] I. Kleinberg, "Controversy: a mixed-bacteria ecological approach to understanding the role of the oral bacteria in dental caries causation: an alternative to Streptococcus mutans and the specific-plaque hypothesis," Critical Reviews in Oral Biology and Medicine, vol. 13, no. 2, pp. 108-125, 2002.

[16] N. Takahashi and B. Nyvad, "The role of bacteria in the caries process: ecological perspectives," Journal of Dental Research, vol. 90, no. 3, pp. 294-303, 2011.

[17] M. R. Becker, B. J. Paster, E. J. Leys et al., "Molecular analysis of bacterial species associated with childhood caries," Journal of Clinical Microbiology, vol. 40, no. 3, pp. 1001-1009, 2002.

[18] J. D. Hillman, S. S. Socransky, and M. Shivers, "The relationships between streptococcal species and periodontopathic bacteria in human dental plaque," Archives of Oral Biology, vol. 30, no. 11-12, pp. 791-795, 1985.

[19] B. Nyvad and M. Kilian, "Comparison of the initial streptococcal microflora on dental enamel in caries-active and in cariesinactive individuals," Caries Research, vol. 24, no. 4, pp. 267272, 1990.

[20] J. Carlsson, "Salivary peroxidase: an important part of our defense against oxygen toxicity," Journal of Oral Pathology, vol. 16, no. 8, pp. 412-416, 1987.

[21] R. Ihalin, V. Loimaranta, M. Lenander-Lumikari, and J. Tenovuo, "The sensitivity of Porphyromonas gingivalis and Fusobacterium nucleatum to different (pseudo)halide-peroxidase combinations compared with mutans streptococci," Journal of Medical Microbiology, vol. 50, no. 1, pp. 42-48, 2001.

[22] K. M. Pruitt, J. Tenovuo, B. Mansson-Rahemtulla, P. Harrington, and D. C. Baldone, "Is thiocyanate peroxidation at equilibrium in vivo?" Biochimica et Biophysica Acta, vol. 870, no. 3, pp. 385-391, 1986.

[23] M. T. Ashby, "Inorganic chemistry of defensive peroxidases in the human oral cavity," Journal of Dental Research, vol. 87, no. 10, pp. 900-914, 2008.

[24] K. M. Pruitt, "The salivary peroxidase system: thermodynamic, kinetic and antibacterial properties," Journal of Oral Pathology, vol. 16, no. 8, pp. 417-420, 1987.

[25] E. L. Thomas, T. W. Milligan, R. E. Joyner, and M. M. Jefferson, "Antibacterial activity of hydrogen peroxide and the lactoperoxidase- hydrogen peroxide-thiocyanate system against oral streptococci," Infection and Immunity, vol. 62, no. 2, pp. 529-535, 1994.

[26] A. Welk, P. Rudolph, J. Kreth, C. Schwahn, A. Kramer, and H. Below, "Microbicidal efficacy of thiocyanate hydrogen peroxide after adding lactoperoxidase under saliva loading in the quantitative suspension test," Archives of Oral Biology, vol. 56, pp. 1576-1582, 2011.

[27] A. Riva, P. Puxeddu, M. Del Fiacco, and F. Testa-Riva, "Ultrastructural localization of endogenous peroxidase in human parotid and submandibular glands," Journal of Anatomy, vol. 127, no. 1, pp. 181-191, 1978.
[28] D. P. Clifford and J. E. Repine, "Hydrogen peroxide mediated killing of bacteria," Molecular and Cellular Biochemistry, vol. 49, no. 3, pp. 143-149, 1982.

[29] N. Ozmeric, "Advances in periodontal disease markers," Clinica Chimica Acta, vol. 343, no. 1-2, pp. 1-16, 2004.

[30] R. Thompson and M. Shibuya, "The inhibitory action of saliva on the diphtheria bacillus; the antibiotic effect of salivary streptococci," Journal of Bacteriology, vol. 51, pp. 671-684, 1946.

[31] A. Garcia-Mendoza, J. Liebana, A. M. Castillo, A. De La Higuera, and G. Piedrola, "Evaluation of the capacity of oral streptococci to produce hydrogen peroxide," Journal of Medical Microbiology, vol. 39, no. 6, pp. 434-439, 1993.

[32] V. S. Lucas, D. Beighton, and G. J. Roberts, "Composition of the oral streptococcal flora in healthy children," Journal of Dentistry, vol. 28, no. 1, pp. 45-50, 2000.

[33] J. Carlsson and M. B. Edlund, "Pyruvate oxidase in Streptococcus sanguis under various growth conditions," Oral Microbiology and Immunology, vol. 2, no. 1, pp. 10-14, 1987.

[34] J. Carlsson, M. B. Edlund, and S. K. Lundmark, "Characteristics of a hydrogen peroxide-forming pyruvate oxidase from Streptococcus sanguis," Oral Microbiology and Immunology, vol. 2, no. 1, pp. 15-20, 1987.

[35] J. Kreth, Y. Zhang, and M. C. Herzberg, "Streptococcal antagonism in oral biofilms: Streptococcus sanguinis and Streptococcus gordonii interference with Streptococcus mutans," Journal of Bacteriology, vol. 190, no. 13, pp. 4632-4640, 2008.

[36] L. Liu, H. Tong, and X. Dong, "Function of the pyruvate oxidase-lactate oxidase cascade in interspecies competition between Streptococcus oligofermentans and Streptococcus mutans," Applied and Environmental Microbiology, vol. 78, pp. 2120-2127, 2012.

[37] H. Tong, W. Chen, J. Merritt, F. Qi, W. Shi, and X. Dong, "Streptococcus oligofermentans inhibits Streptococcus mutans through conversion of lactic acid into inhibitory $\mathrm{H}_{2} \mathrm{O}_{2}$ : a possible counteroffensive strategy for interspecies competition," Molecular Microbiology, vol. 63, no. 3, pp. 872-880, 2007.

[38] H. Tong, W. Chen, W. Shi, F. Qi, and X. Dong, "SO-LAAO, a novel L-amino acid oxidase that enables Streptococcus oligofermentans to outcompete Streptococcus mutans by generating $\mathrm{H}_{2} \mathrm{O}_{2}$ from peptone," Journal of Bacteriology, vol. 190, no. 13, pp. 4716-4721, 2008.

[39] J. M. Boggs, A. H. South, and A. L. Hughes, "Phylogenetic analysis supports horizontal gene transfer of l-amino acid oxidase gene in Streptococcus oligofermentans," Infection, Genetics and Evolution, vol. 12, no. 5, pp. 1005-1009, 2012.

[40] A. J. Lambert and M. D. Brand, "Reactive oxygen species production by mitochondria," Methods in Molecular Biology, vol. 554, pp. 165-181, 2009.

[41] A. A. Starkov, "The role of mitochondria in reactive oxygen species metabolism and signaling," Annals of the New York Academy of Sciences, vol. 1147, pp. 37-52, 2008.

[42] T. L. Leto and M. Geiszt, "Role of Nox family NADPH oxidases in host defense," Antioxidants and Redox Signaling, vol. 8, no. 9-10, pp. 1549-1561, 2006.

[43] A. Vidovic, D. Vidovic Juras, V. Vucicevic Boras et al., "Determination of leucocyte subsets in human saliva by flow cytometry," Archives of Oral Biology, vol. 57, no. 5, pp. 577$583,2012$.

[44] M. Geiszt, J. Witta, J. Baffi, K. Lekstrom, and T. L. Leto, "Dual oxidases represent novel hydrogen peroxide sources supporting mucosal surface host defense," The FASEB Journal, vol. 17, no. 11, pp. 1502-1504, 2003. 
[45] X. Liu, M. M. Ramsey, X. Chen, D. Koley, M. Whiteley, and A. J. Bard, "Real-time mapping of a hydrogen peroxide concentration profile across a polymicrobial bacterial biofilm using scanning electrochemical microscopy," Proceedings of the National Academy of Sciences of the United States of America, vol. 108, no. 7, pp. 2668-2673, 2011.

[46] P. T. M. Nguyen, J. Abranches, T. N. Phan, and R. E. Marquis, "Repressed respiration of oral streptococci grown in biofilms," Current Microbiology, vol. 44, no. 4, pp. 262-266, 2002.

[47] C. Robinson, "Mass transfer of therapeutics through natural human plaque biofilms. A model for therapeutic delivery to pathological bacterial biofilms," Archives of Oral Biology, vol. 56, pp. 829-836, 2011.

[48] T. Thurnheer, R. Gmür, S. Shapiro, and B. Guggenheim, "Mass transport of macromolecules within an in vitro model of supragingival plaque," Applied and Environmental Microbiology, vol. 69, no. 3, pp. 1702-1709, 2003.

[49] D. G. Cvitkovitch, "Genetic competence and transformation in oral streptococci," Critical Reviews in Oral Biology and Medicine, vol. 12, no. 3, pp. 217-243, 2001.

[50] J. P. Claverys, M. Prudhomme, and B. Martin, "Induction of competence regulons as a general response to stress in grampositive bacteria," Annual Review of Microbiology, vol. 60, pp. 451-475, 2006.

[51] Y. Liu and R. A. Burne, "Multiple two-component systems modulate alkali generation in Streptococcus gordonii in response to environmental stresses," Journal of Bacteriology, vol. 191, no. 23, pp. 7353-7362, 2009.

[52] Y. Liu, Y. Dong, Y. Y. M. Chen, and R. A. Burne, "Environmental and growth phase regulation of the Streptococcus gordonii arginine deiminase genes," Applied and Environmental Microbiology, vol. 74, no. 16, pp. 5023-5030, 2008.

[53] D. Perry and H. K. Kuramitsu, "Genetic transformation of Streptococcus mutans," Infection and Immunity, vol. 32, no. 3, pp. 1295-1297, 1981.

[54] J. P. Claverys, B. Martin, and P. Polard, "The genetic transformation machinery: composition, localization, and mechanism," FEMS Microbiology Reviews, vol. 33, no. 3, pp. 643656, 2009.

[55] O. Johnsborg and L. S. Håvarstein, "Regulation of natural genetic transformation and acquisition of transforming DNA in Streptococcus pneumoniae," FEMS Microbiology Reviews, vol. 33, no. 3, pp. 627-642, 2009.

[56] D. G. Cvitkovitch and D. Senadheera, "Quorum sensing and biofilm formation by Streptococcus mutans," Advances in Experimental Medicine and Biology, vol. 631, pp. 178-188, 2008.

[57] J. Kreth, H. Vu, Y. Zhang, and M. C. Herzberg, "Characterization of hydrogen peroxide-induced DNA release by Streptococcus sanguinis and Streptococcus gordonii," Journal of Bacteriology, vol. 191, no. 20, pp. 6281-6291, 2009.

[58] A. Itzek, L. Zheng, Z. Chen, J. Merritt, and J. Kreth, "Hydrogen peroxide-dependent DNA release and transfer of antibiotic resistance genes in Streptococcus gordonii," Journal of Bacteriology, vol. 193, pp. 6912-6922, 2011.

[59] L. Zheng, A. Itzek, Z. Chen, and J. Kreth, "Environmental influences on competitive hydrogen peroxide production in Streptococcus gordonii," Applied and Environmental Microbiology, vol. 77, no. 13, pp. 4318-4328, 2011.

[60] L. Y. Zheng, A. Itzek, Z. Y. Chen, and J. Kreth, "Oxygen dependent pyruvate oxidase expression and production in Streptococcus sanguinis," International Journal of Oral Science, vol. 3, no. 2, pp. 82-89, 2011.
[61] Y. Liu and R. A. Burne, "The major autolysin of Streptococcus gordonii is subject to complex regulation and modulates stress tolerance, biofilm formation, and extracellular-DNA release," Journal of Bacteriology, vol. 193, no. 11, pp. 2826-2837, 2011.

[62] K. H. Berg, H. S. Ohnstad, and L. S. Havarstein, "LytF, a novel competence-regulated murein hydrolase in the genus Streptococcus," Journal of Bacteriology, vol. 194, pp. 627-635, 2012.

[63] M. Prudhomme, L. Attaiech, G. Sanchez, B. Martin, and J. P. Claverys, "Antibiotic stress induces genetic transformability in the human pathogen streptoccus pneumoniae," Science, vol. 313, no. 5783, pp. 89-92, 2006.

[64] H. C. Flemming and J. Wingender, "The biofilm matrix," Nature Reviews Microbiology, vol. 8, no. 9, pp. 623-633, 2010.

[65] T. Das, P. K. Sharma, H. J. Busscher, H. C. Van Der Mei, and B. P. Krom, "Role of extracellular DNA in initial bacterial adhesion and surface aggregation," Applied and Environmental Microbiology, vol. 76, no. 10, pp. 3405-3408, 2010.

[66] T. Das, P. K. Sharma, B. P. Krom, H. C. van der Mei, and H. J. Busscher, "Role of eDNA on the adhesion forces between Streptococcus mutans and substratum surfaces: influence of ionic strength and substratum hydrophobicity," Langmuir, vol. 27, pp. 10113-10118, 2011.

[67] D. M. Dominiak, J. L. Nielsen, and P. H. Nielsen, "Extracellular DNA is abundant and important for microcolony strength in mixed microbial biofilms," Environmental Microbiology, vol. 13, no. 3, pp. 710-721, 2011.

[68] J. Zhang, H. C. Tong, X. Z. Dong, L. Yue, and X. J. Gao, “A preliminary study of biological characteristics of Streptococcus oligofermentans in oral microecology," Caries Research, vol. 44, no. 4, pp. 345-348, 2010.

[69] N. S. Jakubovics, S. R. Gill, S. E. Iobst, M. M. Vickerman, and P. E. Kolenbrander, "Regulation of gene expression in a mixedgenus community: stabilized arginine biosynthesis in streptococcus gordonii by coaggregation with Actinomyces naeslundii," Journal of Bacteriology, vol. 190, no. 10, pp. 3646-3657, 2008.

[70] N. S. Jakubovics, S. R. Gill, M. M. Vickerman, and P. E. Kolenbrander, "Role of hydrogen peroxide in competition and cooperation between Streptococcus gordonii and Actinomyces naeslundii," FEMS Microbiology Ecology, vol. 66, no. 3, pp. 637-644, 2008.

[71] R. J. Palmer Jr., P. I. Diaz, and P. E. Kolenbrander, "Rapid succession within the Veillonella population of a developing human oral biofilm in situ," Journal of Bacteriology, vol. 188, no. 11, pp. 4117-4124, 2006.

[72] J. Liu, C. Wu, I. H. Huang, J. Merritt, and F. Qi, "Differential response of Streptococcus mutans towards friend and foe in mixed-species cultures," Microbiology, vol. 157, pp. 24332444, 2011.

[73] S. B. I. Luppens, D. Kara, L. Bandounas et al., "Effect of Veillonella parvula on the antimicrobial resistance and gene expression of Streptococcus mutans grown in a dual-species biofilm," Oral Microbiology and Immunology, vol. 23, no. 3, pp. 183-189, 2008.

[74] C. Palmer, E. M. Bik, M. B. Eisen et al., "Rapid quantitative profiling of complex microbial populations," Nucleic Acids Research, vol. 34, no. 1, article e5, 2006.

[75] J. P. Barnard and M. W. Stinson, "Influence of environmental conditions on hydrogen peroxide formation by Streptococcus gordonii," Infection and Immunity, vol. 67, no. 12, pp. 65586564, 1999.

[76] B. Görke and J. Stülke, "Carbon catabolite repression in bacteria: many ways to make the most out of nutrients," Nature Reviews Microbiology, vol. 6, no. 8, pp. 613-624, 2008. 
[77] L. Zheng, Z. Chen, A. Itzek, M. Ashby, and J. Kreth, "Catabolite control protein a controls hydrogen peroxide production and cell death in Streptococcus sanguinis," Journal of Bacteriology, vol. 193, no. 2, pp. 516-526, 2011.

[78] L. Chen, X. Ge, Y. Dou, X. Wang, J. R. Patel, and P. Xu, "Identification of hydrogen peroxide productionrelated genes in Streptococcus sanguinis and their functional relationship with pyruvate oxidase," Microbiology, vol. 157, no. 1, pp. 1320, 2011.

[79] S. Ramos-Montañez, H. C. T. Tsui, K. J. Wayne et al., "Polymorphism and regulation of the $s p x B$ (pyruvate oxidase) virulence factor gene by a CBS-HotDog domain protein (SpxR) in serotype 2 Streptococcus pneumoniae," Molecular Microbiology, vol. 67, no. 4, pp. 729-746, 2008.

[80] M. M. Ramsey and M. Whiteley, "Polymicrobial interactions stimulate resistance to host innate immunity through metabolite perception," Proceedings of the National Academy of Sciences of the United States of America, vol. 106, no. 5, pp. 1578-1583, 2009.

[81] S. A. Brown and M. Whiteley, "A novel exclusion mechanism for carbon resource partitioning in Aggregatibacter actinomycetemcomitans," Journal of Bacteriology, vol. 189, no. 17, pp. 6407-6414, 2007.

[82] J. M. Tanzer, A. Thompson, K. Sharma, M. M. Vickerman, E. M. Haase, and F. A. Scannapieco, "Streptococcus mutans Outcompetes Streptococcus gordonii in vivo," Journal of Dental Research, vol. 91, no. 5, pp. 513-519, 2012. 


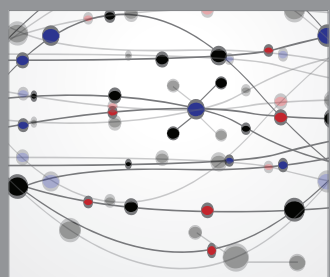

The Scientific World Journal
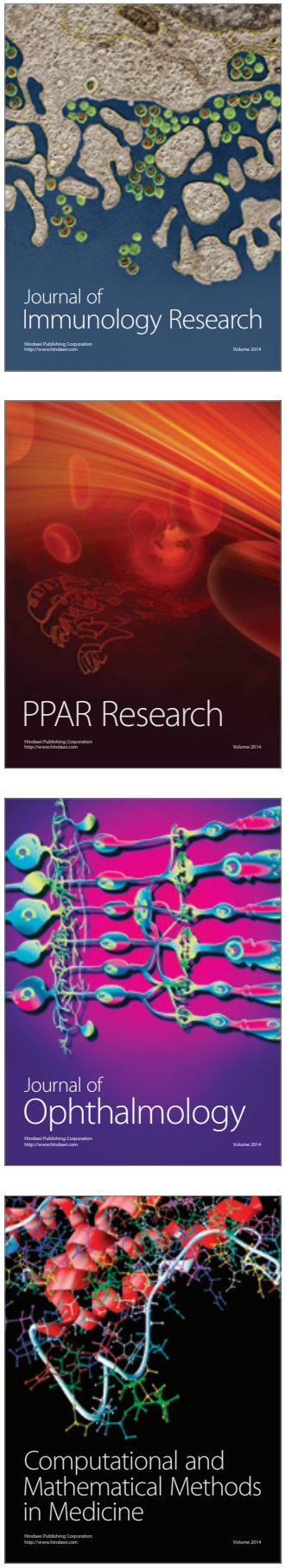

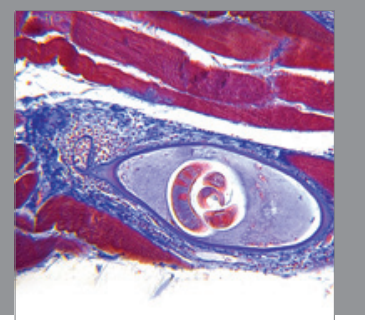

Gastroenterology

Research and Practice
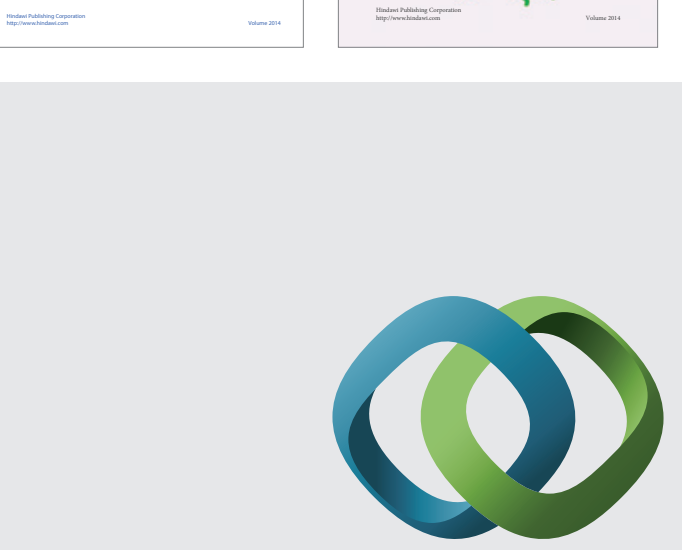

\section{Hindawi}

Submit your manuscripts at

http://www.hindawi.com
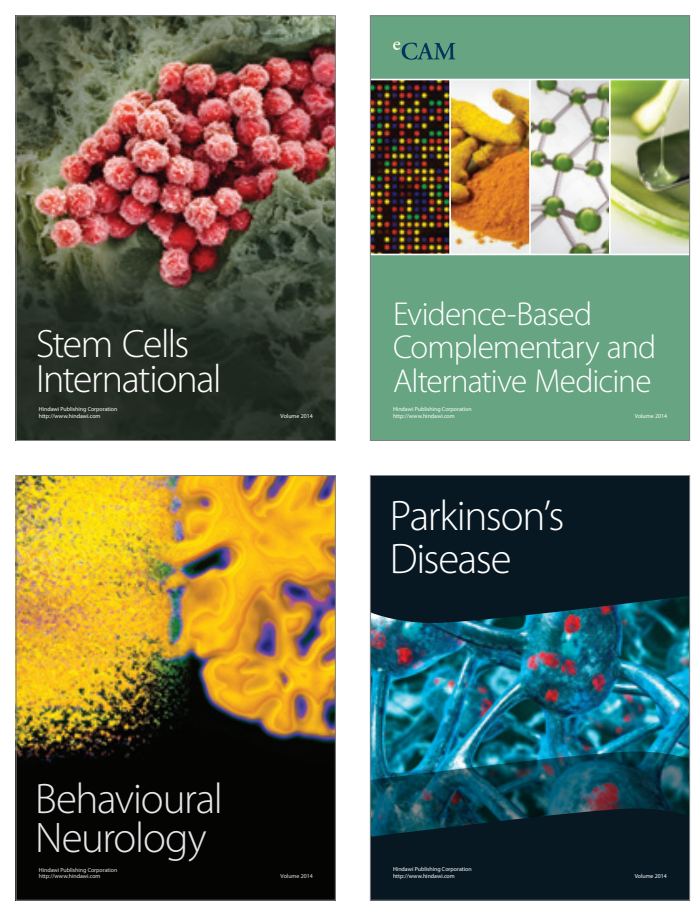

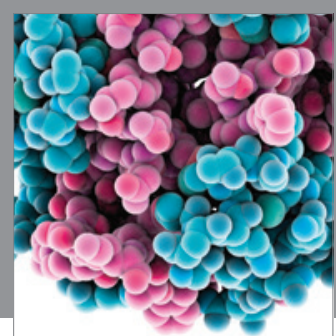

Journal of
Diabetes Research

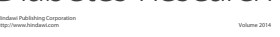

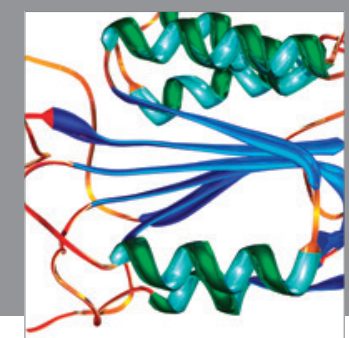

Disease Markers
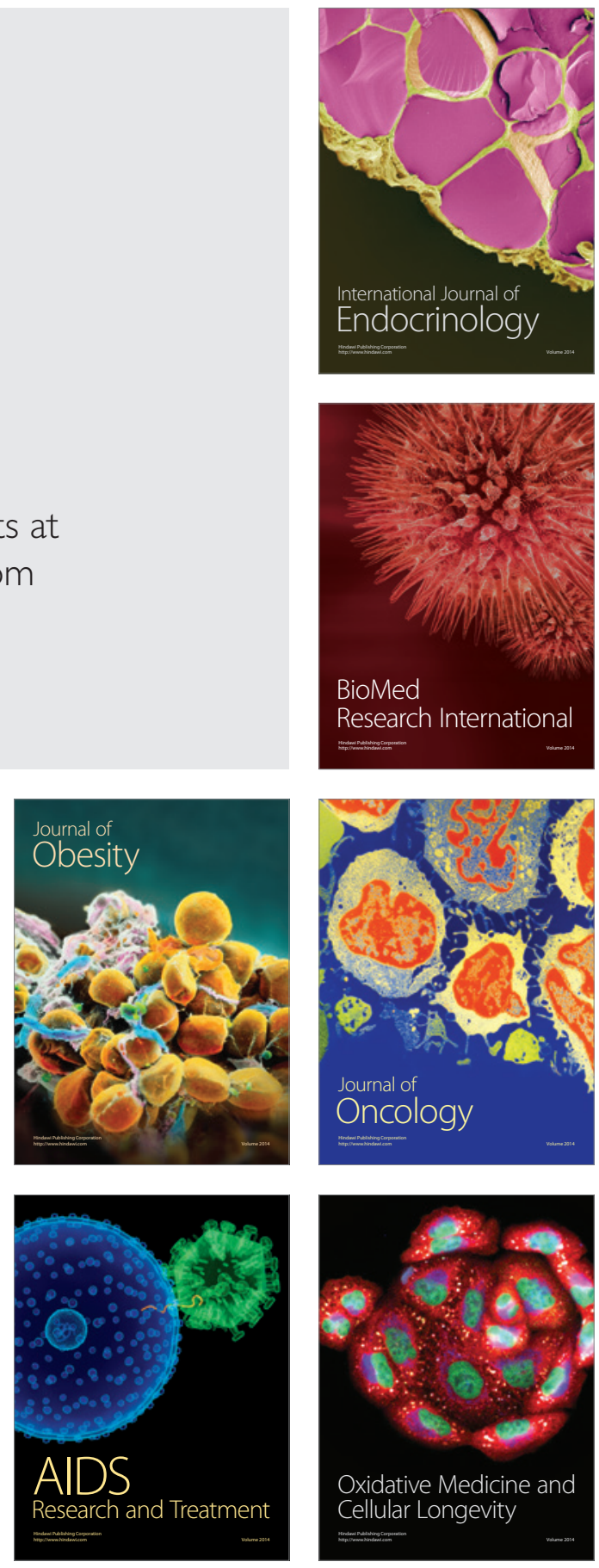